Fifth International Conference on Sustainable Construction Materials and

Technologies. http://www.claisse.info/Proceedings.htm

\title{
EXPERIMENTAL AND ANALYTICAL STUDIES ON \\ CRACKING DUE TO CORROSION IN REINFORCED \\ CONCRETE SLAB
}

Hiroyuki Nakagawa ${ }^{1}$, Hiroki Yamaguchi ${ }^{2}$, Manabu Matsushima ${ }^{3}$

${ }^{1}$ Dep. of Civil Eng., Shikoku Research Institute Inc., 2109-8, Yashimanishi, Takamatsu, Kagawa, 761-0192, Japan, nakagawa@ssken.co.jp

${ }^{2}$ Dep. of Civil Eng., Shikoku Electric Power Co., Inc., 2-5, Marunouchi, Takamatsu, Kagawa, 2-5, Japan, yamaguchi16483@yonden.co.jp

${ }^{3}$ Professor, Dep. of Civil Eng., Kagawa University, 2217-20, Hayashi-cho, Takamatsu, Kagawa, 761-0396, Japan, matusima@eng.kagawa-u.ac.jp

\begin{abstract}
This paper aims to present both experimental and analytical studies of reinforced concrete (RC) slabs embedded with multiple reinforcing bars. Crack initiation patterns and crack propagation due to the corrosion of rebar were investigated for RC slabs. The rebar spacing of specimens in this study was $60 \mathrm{~mm}, 120 \mathrm{~mm}$ and $240 \mathrm{~mm}$. Results from electrolytic corrosion experiments, revealed that crack initiation patterns were influenced by concrete depth and rebar spacing. Additionally, crack propagation was more dominant in the horizontal direction than the occurrence pattern. The corrosion weight loss of rebar for initial crack growth cracks was approximately $50 \mathrm{mg} / \mathrm{cm}^{2}$ in this study. For crack initiation patterns and crack propagation, similar results were obtained by numerical analysis.
\end{abstract}

Keywords. corrosion, concrete slab, multiple reinforcing bars, crack propagation, delamination

\section{INTRODUCTION}

Steel bars embedded in concrete normally do not corrode because the alkaline environment of concrete surrounding reinforcing steels results in the formation of a passive film on the steel surface, which in turn, can protect the steels from corrosion. 
However, Japan is an island country surrounded by the sea on all sides. Chloride ions from marine environments penetrate into the concrete and break the protective film on the reinforcing steels causing the steels embedded in the concrete to corrode.

Corrosion often leads to cracking and spalling of concrete due to the production of rust, which occupies a greater volume than the steel that produced it. If the concrete covering the rebars is relatively shallow, and/or the rebars are widely spaced, cracks form perpendicular to the concrete surface (Figure 1a). However, if the concrete covering the rebars is relatively deep, and/or the rebars are closely spaced, cracks form parallel with the concrete surface (Figure $1 b)^{1), 2}$. Figure 2 shows the propagation of cracks that follow the line of rebar in a concrete beam. The cracks are due to a thin cover of concrete at the bottom of the beam and are expected to expand over time.

Concrete delamination however, occurs from the propagation of horizontal cracks between the rusted rebar and an obvious lack of concrete cover in the case of a slab (Figure 3). The propagation of horizontal cracks is dominant even with a wide spacing of rebars and a slight cover of concrete (Figure 4). TRAN et al (2012) analyzed crack propagations due to multi-rebar corrosion using a discrete numerical analysis method ${ }^{3)}$. An analyzed model with $200 \mathrm{~mm}$ interval of rebar, and $40 \mathrm{~mm}$ caver depth, was delaminated due to propagation of internal cracks between the reinforcing bars. On the one hand, an experimental study using a concrete slab embedded with multiple reinforcing bars was not conducted.

In this study, experimental and analytical parameter studies were carried out for reinforced concrete slabs in order to investigate crack initiation and crack propagation due to corrosion.

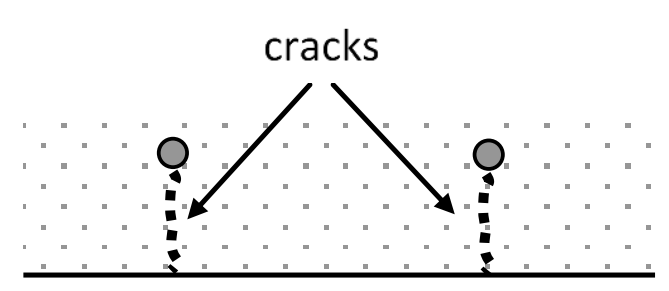

(a) Perpendicular crack

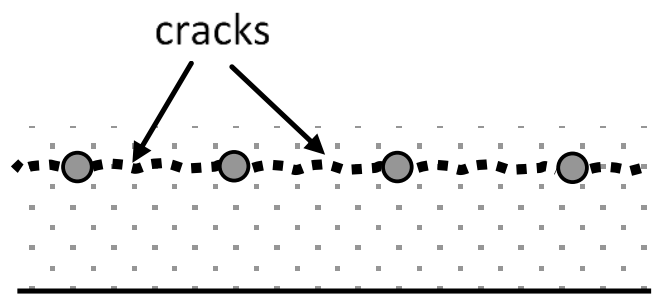

(b) Horizontal crack

Figure 1. Initial crack patterns 


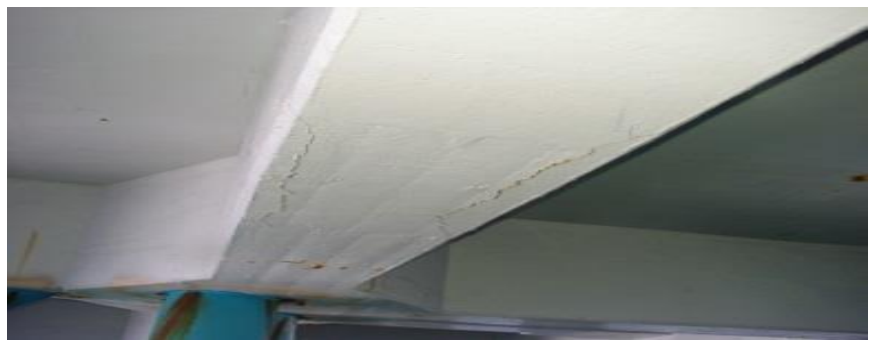

Figure 2. Cracks of a beam

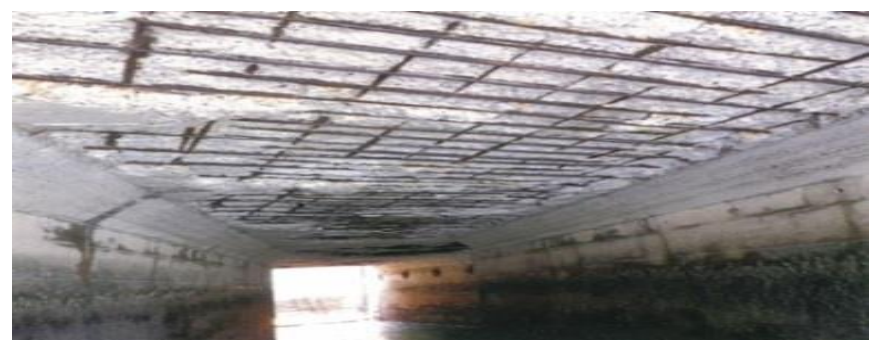

Figure 3. Delamination of a slab

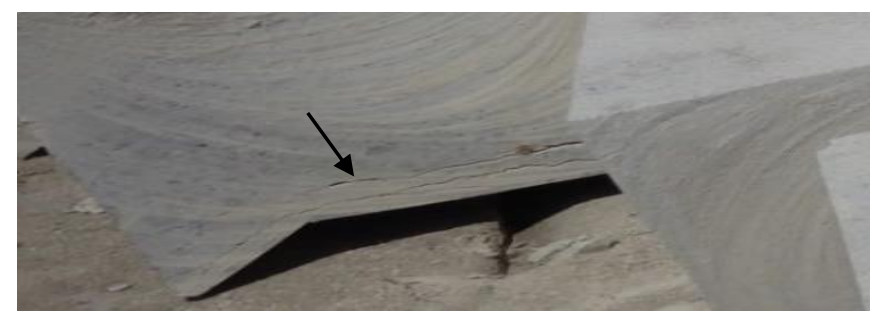

Figure 4. Horizontal cracks

\section{EXPERIMENTAL PROGRAM}

\section{Reinforced Concrete Slab Description}

The test specimens were $400 \mathrm{~mm}$ long slabs with $900 \times 180 \mathrm{~mm}^{2}$ rectangular cross sections. $19 \mathrm{~mm}$ deformed steel bars were embedded in the slabs with varied spacing (Figure 5). Two or three $16 \mathrm{~mm}$ deformed steel bars were set at right angles to the reinforcing bars (Figure 6). The distance between the undersurface of the rebar and the bottom face of the slab was $30 \mathrm{~mm}$ and the distances between the steel bars were 60 $\mathrm{mm}, 120 \mathrm{~mm}$ and $240 \mathrm{~mm}$ (Figure 7). The mixture proportion of the concrete used is summarized in Table 1. The compressive strength was $36.9 \mathrm{MPa}$ (28 days). For the $120 \mathrm{~mm}$ spacing and the $240 \mathrm{~mm}$ spacing, two identical specimens were casted. 


\section{Accelerated Corrosion Tests}

An applied current was used to accelerate the corrosion of the rebars. The RC slab was placed in a PVC tank containing an alkaline salted solution $(30 \mathrm{~g} / \mathrm{L} \mathrm{NaCl})$, and the bars were polarized anodically using a counter electrode to enhance corrosion (Figure 8). The counter electrode, made from a stainless steel plate, was placed at the bottom of the slab using a rigid sponge.

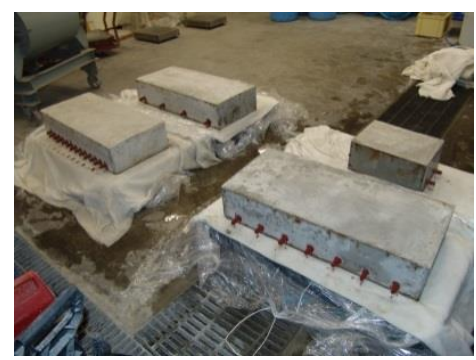

Figure 5. Specimens

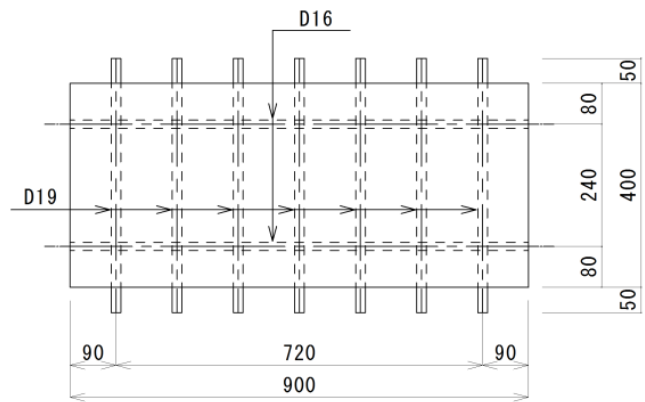

Figure 6. Size and details of specimens (Plane view, unit: $\mathrm{mm}$ )

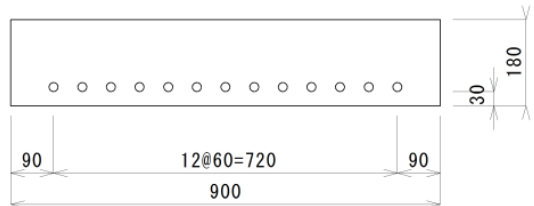

(a) $60 \mathrm{~mm}$ Spacing

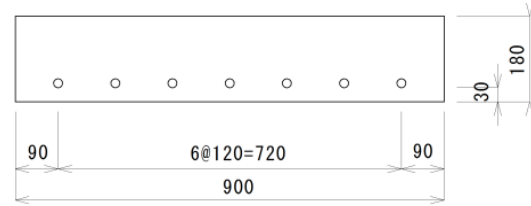

(b) $120 \mathrm{~mm}$ Spacing

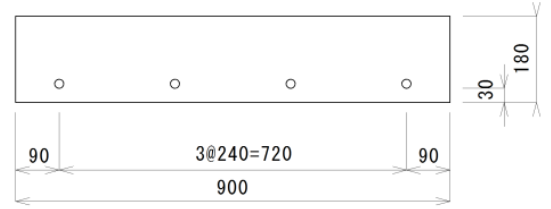

(c) $240 \mathrm{~mm}$ Spacing

Figure 7. Size and details of specimens

(Sectional view, unit: $\mathrm{mm}$ )

Table 1. Mixture proportion

\begin{tabular}{|c|c|c|c|c|c|c|c|c|c|c|c|}
\hline \multirow{2}{*}{ G.max } & \multirow{2}{*}{$\mathrm{W} / \mathrm{C}$} & \multirow{2}{*}{ Slump } & \multirow{2}{*}{$\begin{array}{c}\text { Air } \\
\text { content }\end{array}$} & \multirow{2}{*}{$\mathrm{s} / \mathrm{a}$} & \multicolumn{5}{|c|}{ Unit weight $\left(\mathrm{kg} / \mathrm{m}^{3}\right)$} & \multirow{2}{*}{$\begin{array}{c}\text { AE-Water } \\
\text { Reducing Agent }\end{array}$} & \multirow{2}{*}{$\begin{array}{c}\mathrm{AE} \\
\text { Entrainew }\end{array}$} \\
\hline & & & & & \multirow{2}{*}{ Cement } & \multirow{2}{*}{ Water } & \multirow{2}{*}{$\begin{array}{c}\text { Fine } \\
\text { Aggregate 1 }\end{array}$} & \multirow{2}{*}{$\begin{array}{c}\text { Fine } \\
\text { Aggregate 2 }\end{array}$} & \multirow{2}{*}{\begin{tabular}{|c} 
Coarse \\
Aggregate
\end{tabular}} & & \\
\hline$(\mathrm{mm})$ & (wt $\%)$ & $(\mathrm{cm})$ & $(\mathrm{vol} \%)$ & $(\mathrm{wt} \%)$ & & & & & & $\mathrm{C} \times(\%)$ & $\mathrm{C} \times(\%)$ \\
\hline 20 & 54 & $8 \pm 2.5$ & $4.5 \pm 1.5$ & 45.2 & 282 & 155 & 610 & 262 & 1056 & 0.6 & 0.003 \\
\hline
\end{tabular}

A power supply delivered a constant current density of $1.0 \mathrm{~mA} / \mathrm{cm}^{2}$ between the reinforcing bars and the counter electrode. Insulating the crossing rebar was implemented to ensure that only the embedded reinforcing bars were affected. A schematic representation of the accelerated corrosion testing setup is depicted in Figure 9.

\section{Crack Initiation Tests}

After starting the electric corrosion test, crack patterns were observed on the bottom surfaces and sides of the specimens. The corrosion weight loss of the embedded rebar was measured when the crack initiation was located. 


\section{Measurement of Corrosion Amount}

After the accelerated corrosion test, the concrete of the specimen was crushed and the embedded rebars were taken out to measure weight loss. The reinforcing bars were cleaned with $10 \%$ diammonium hydrogen citrate solution to ensure that all corrosion products were washed away, then weighed. A sound rebar without corrosion was also weighed as a control.

The weight loss was calculated as follows,

$$
\Delta W=\frac{W_{0} \cdot L_{r}-W_{1}}{A_{r}}
$$

Where $\Delta W$ is the weight loss of corrosion rebar $\left(\mathrm{mg} / \mathrm{cm}^{2}\right), W_{0}$ is the weight per unit length of sound rebar without the protective oxide layer on the rebar $(\mathrm{mg} / \mathrm{cm}), W_{1}$ is the measured weight of the corrosion rebar after removal of corrosion products $(\mathrm{mg})$, $L_{r}$ is the rebar length $(\mathrm{cm})$ and $A_{r}$ is the surface area of the rebar $\left(\mathrm{cm}^{2}\right)$.

\section{Crack Propagation Tests}

Specimens under the same conditions used in the crack initiation tests, were viewed for crack propagations without a break. After confirmation of crack propagation, the weight loss of the rebar in the specimen was measured.

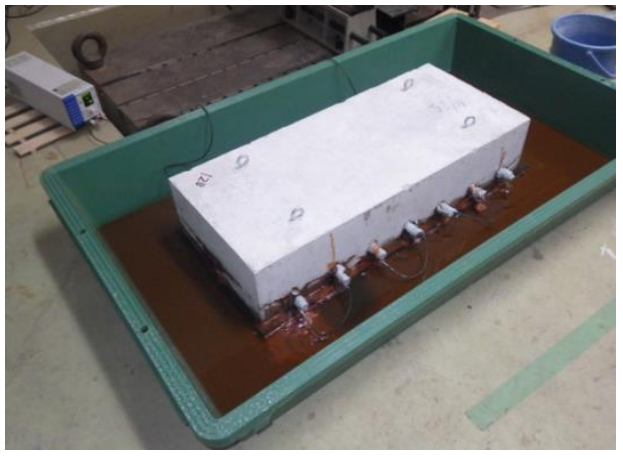

Figure 8. Electric corrosion test

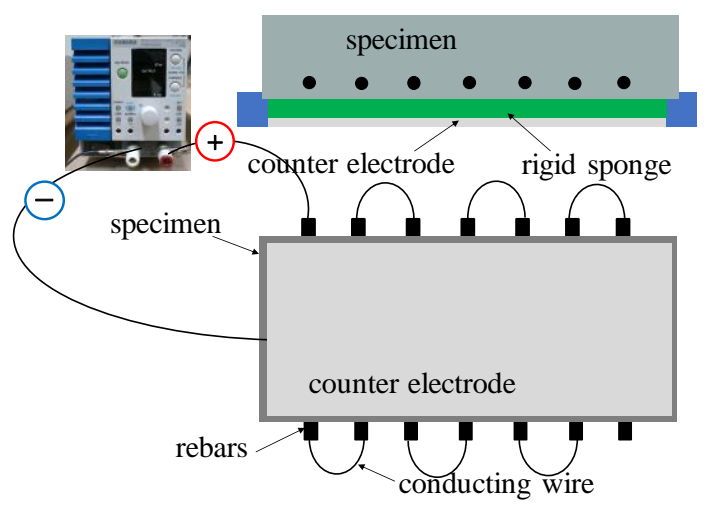

Figure 9. Scheme of the accelerated corrosion set up

\section{EXPERIMETAL RESULTS}

\section{Crack Initiation Results}

Due to the swelling caused by corrosion products, cracks appeared from the steel/concrete interface and propagated in different patterns (Figure 10). For the specimen with $60 \mathrm{~mm}$ spacing, cracks initially appeared in the horizontal direction between the bars (Figure 10a). For specimens with $120 \mathrm{~mm}$ and $240 \mathrm{~mm}$ spacing, cracks initially appeared in the vertical direction below some bars at the bottom of the specimen (Figure 10b and Figure 10c). The weight loss of the rebar after corrosion is 
shown in Table 2. The weight of the protective oxide layer on the sound rebar was $22.77 \mathrm{mg} / \mathrm{cm}^{2}$. The weight of the corroded rebar was $42.91 \sim 50.52 \mathrm{mg} / \mathrm{cm}^{2}$.

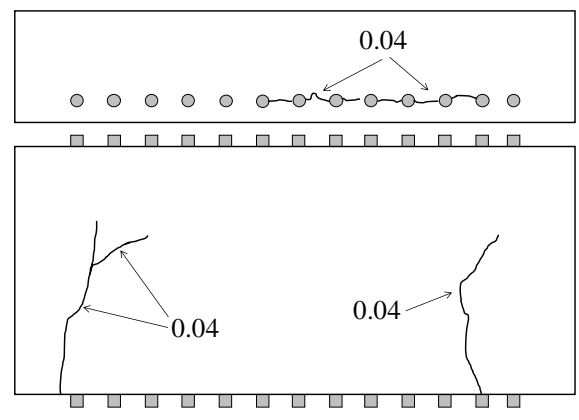

(a) $60 \mathrm{~mm}$ Spacing

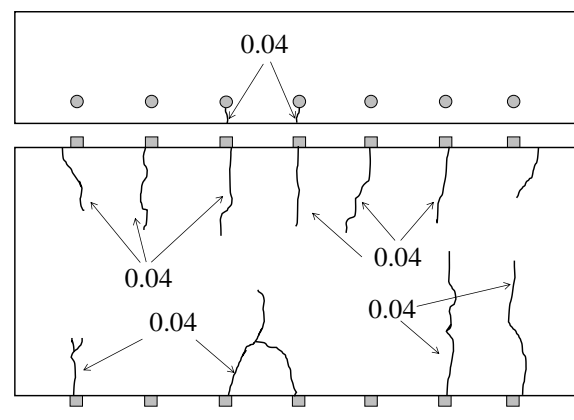

(b) $120 \mathrm{~mm}$ Spacing

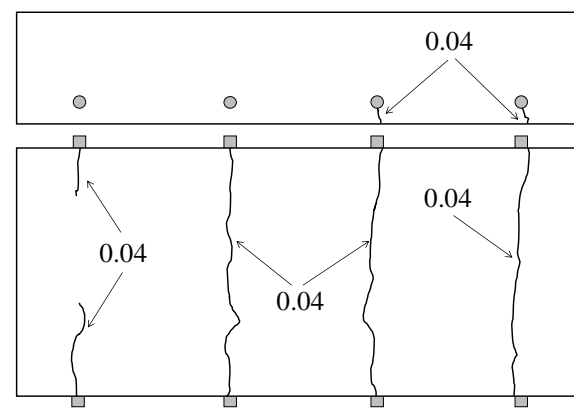

(c) $240 \mathrm{~mm}$ Spacing

Figure 10. Sketches of the initial crack patterns and crack widths (unit: mm)

Table 2. Weight loss of corrosion reinforcing bars

\begin{tabular}{|c|c|c|c|}
\hline & D19ctc60 & D19ctc120 & D19ctc240 \\
\hline Measured value & 72.58 & 73.29 & 65.68 \\
\hline $\begin{array}{c}\text { Protective oxide } \\
\text { laver }\end{array}$ & \multicolumn{3}{|c|}{22.77} \\
\hline $\begin{array}{c}\text { Weight loss of } \\
\text { corrosion rebar }\end{array}$ & 49.81 & 50.52 & 42.91 \\
\hline
\end{tabular}

\section{Crack Propagation Results}

The accelerated corrosion test was conducted for 670 hours at $1.7 \mathrm{~A}$. The rebars were numbered 1 7. Figure 11 shows crack patterns on the specimen with $120 \mathrm{~mm}$ spacing. Sketched crack patterns and crack widths are shown in Figure 12. On the end surface, cracks initially appeared in the vertical direction, followed by horizontal cracks propagating between the bars. Slight inclined cracks were observed at bars 1 and 7 which propagated towards the side surfaces of the concrete (Figure 12a). The width of the horizontal cracks ranged from $0.20 \mathrm{~mm} \sim 0.85 \mathrm{~mm}$. On the bottom surface, the 
largest crack width along rebars 1 and 7 was $1.50 \mathrm{~mm}$. Crack widths along rebars 2 6 however, did not exceed $0.15 \mathrm{~mm}$.

Figure 13 shows crack patterns on the specimen with $240 \mathrm{~mm}$ spacing. The accelerated corrosion test was continued for 857 hours at 1.0A The rebars were numbered 1 4. Sketched crack patterns and crack widths are shown in Figure 14. We were not able to measure the crack width on the end surface because it peeled off (Figure 13). The crack patterns were similar to the specimen with $120 \mathrm{~mm}$ spacing in that the initial vertical cracks did not widen. However, the horizontal cracks extended along the bars with corrosive progression.

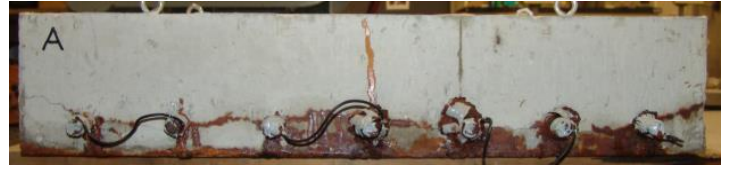

(a) End surface

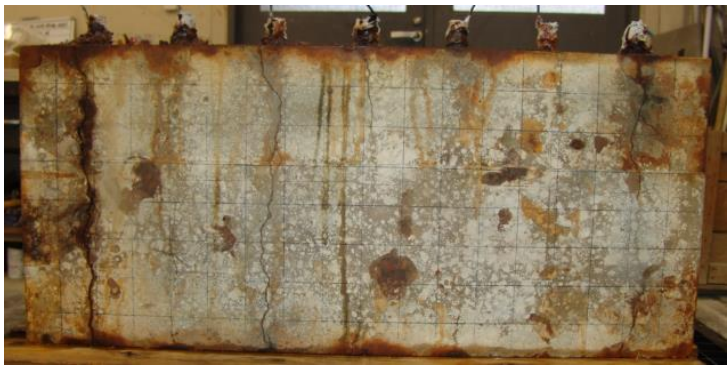

(b) Bottom surface

Figure 11. Crack patterns of the specimen with $120 \mathrm{~mm}$ interval

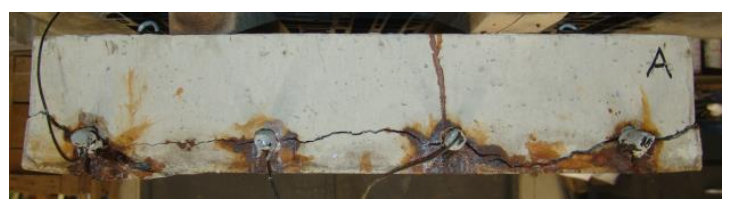

(a) End surface

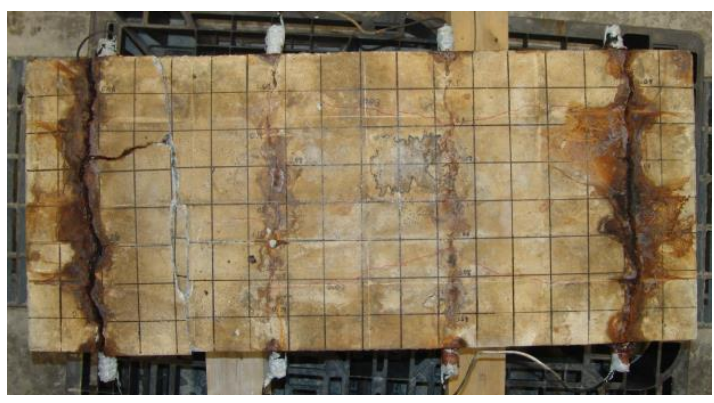

(b) Bottom surface

Figure 13. Crack patterns of the specimen with $240 \mathrm{~mm}$ interval

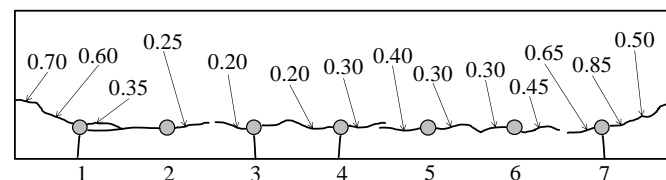

(a) End surface

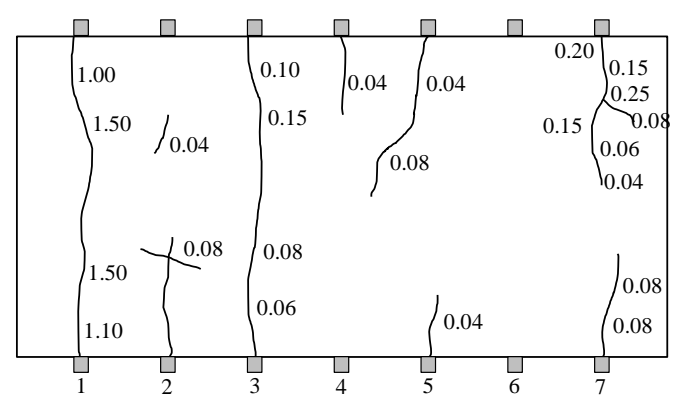

(b) Bottom surface

Figure 12. Crack sketches and crack widths of the specimen with $120 \mathrm{~mm}$ interval (unit: $\mathrm{mm}$ )

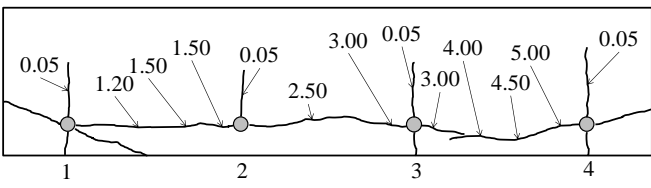

(a) End surface

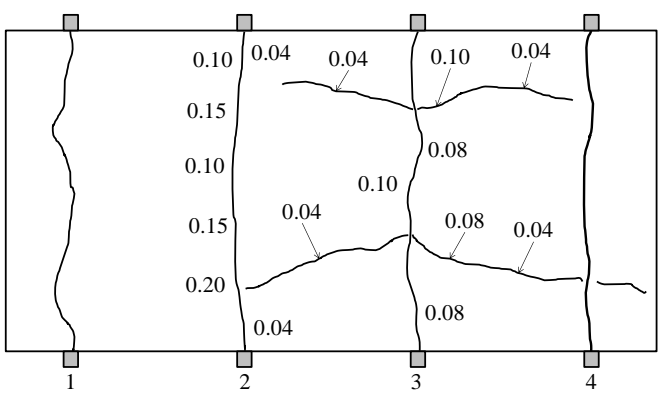

(b) Bottom surface

Figure 14. Crack sketches and crack widths of the specimen with $240 \mathrm{~mm}$ interval (unit: $\mathrm{mm}$ ) 


\section{EXPERIMENTAL DISCUSSION}

Results from the crack initiation tests confirmed that rebar spacing affects crack initiation patterns in cases of multi-rebar corrosion. If the rebars are closely spaced such as the specimen with $60 \mathrm{~mm}$ spacing, the initial cracks form parallel with the concrete surface. If the concrete cover depth is relatively shallow, and/or the reinforcing bars are widely spaced such as the specimens with $120 \mathrm{~mm}$ and $240 \mathrm{~mm}$ spacing, the initial cracks are aligned with the reinforcing bars and are perpendicular with the concrete surface. Moreover, the corrosion amount at occurrence of corrosion cracks was approximately $50 \mathrm{mg} / \mathrm{cm}^{2}$ in this study.

The crack propagation tests revealed that propagation was dominant in the horizontal direction between the reinforcing bars. The internal radial stress caused by rust expansion acted on the concrete around the reinforcing bars. The reinforcing bars at the left and right ends have no binding force to counteract a lateral force of corrosion expansion. Therefore, it is easier to expand the widths of crack perpendicular to the concrete surface. Conversely, for the central rebars, a lateral force due to corrosion expansion is suppressed in the surrounding concrete. As a result, a vertical action due to corrosion expansion dominates, thus horizontal cracks occurred between the reinforcing bars.

\section{NUMERICAL ANALYSIS}

In order to confirm the experimental results, a numerical analysis was examined on corrosion cracks of the specimens.

\section{Finite Element Modeling}

The aim of the numerical simulation is to estimate the propagation of cracks from concrete with different rebar spacing. Analyzed specimens were modeled as shown in Figure 15. Due to the limitation of numerical computation, the specimen's length is 5 $\mathrm{mm}$ utilizing it as a plane strain model in this analysis. The specimens are simply supported on the other side of the concrete cover (Figure 16). The analysis uses a concrete material model whereby the tensile behavior of concrete up to the tensile strength is modeled as linear elastic (Figure 17). A bilinear softening branch is assumed after cracking, in which $f_{t}$ is tensile strength and $G_{F}$ is tensile fracture energy. 


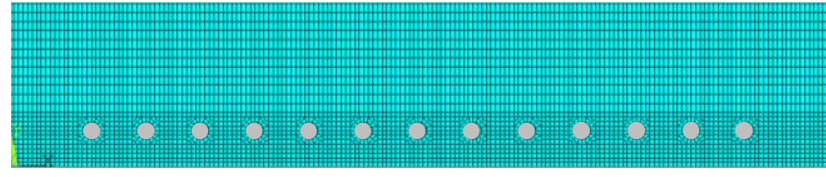

(a) $60 \mathrm{~mm}$ Spacing

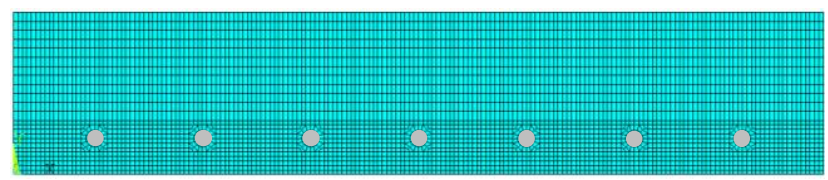

(b) $120 \mathrm{~mm}$ Spacing

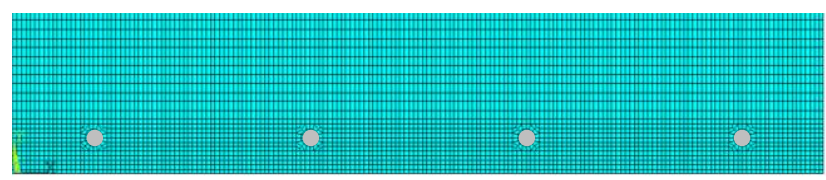

(c) $240 \mathrm{~mm}$ Spacing

Figure 15. Analytical models of specimens

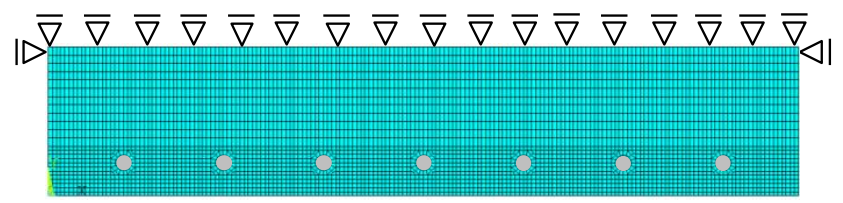

Figure 16. Specimen supports

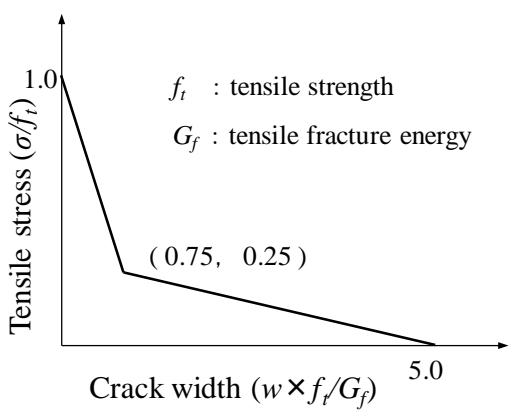

Figure 17. Concrete model

\begin{tabular}{|c|c|}
\hline \multicolumn{2}{|c|}{ ICdiable $\mathbf{\beta}$. Material property } \\
\hline $\begin{array}{c}\text { Elastic modulus } \\
E_{c}(\mathrm{GPa})\end{array}$ & 15 \\
\hline $\begin{array}{c}\text { Poisson ratio } \\
v_{c} \\
\end{array}$ & 0.2 \\
\hline $\begin{array}{c}\text { Tensile strength } \\
f_{t}(\mathrm{MPa}) \\
\end{array}$ & 2.75 \\
\hline $\begin{array}{c}\text { Compressive strength } \\
f^{\prime}{ }_{c}(\mathrm{MPa})\end{array}$ & 36.9 \\
\hline \multicolumn{2}{|l|}{ 【Reinfocing bar】 } \\
\hline $\begin{array}{c}\text { Elastic modulus } \\
E_{s}(\mathrm{GPa}) \\
\end{array}$ & 200 \\
\hline $\begin{array}{c}\text { Poisson ratio } \\
v_{s} \\
\end{array}$ & 0.2 \\
\hline $\begin{array}{c}\text { Diameter of steel } \\
\varphi(\mathrm{mm})\end{array}$ & 19 \\
\hline
\end{tabular}

\section{Material Property}

Table 3 shows the material properties that are used in the analysis. The parameters of concrete material were identified from the experimental measurements performed on concrete specimens. To consider creep deformation, the elastic modulus of concrete is as follows:

$$
E_{c r}=\frac{1}{1+C_{r}} E_{r}
$$

Where $E_{c r}$ is the elastic modulus of concrete for this analysis, $E_{c}$ is the elastic modulus of the experimental result, and $C_{r}$ is the creep factor, set at 1.0.

The shear transferring capacity at the cracked interface is taken here as a transfer coefficient.

\section{Corrosion Expansion Model}


Rust expansion occurred by applying heat to the steel rebar. The thermal expansion coefficient of the reinforcing bar was $1.0 \times 10^{-5} /{ }^{\circ} \mathrm{C}$. The input temperature was gradually increased in increments of $0.2{ }^{\circ} \mathrm{C}$.

\section{Analytical Crack Initiation Results}

Crack patterns occurred at an early stage for the specimens with $60 \mathrm{~mm}, 120 \mathrm{~mm}$ and $240 \mathrm{~mm}$ spacing (Figure 18). The dotted lines in the figures represent the areas where the stress in the concrete reached the tensile strength, due to the inflation pressure. For the rebar spacing of $60 \mathrm{~mm}$, cracks occurred initially in the horizontal direction between the bars (Figure 18a). For the rebar spacing of $120 \mathrm{~mm}$ and $240 \mathrm{~mm}$, cracks appeared initially in the vertical direction below some bars (Figure 18b and Figure 18c). These results were similar to the experimental results.

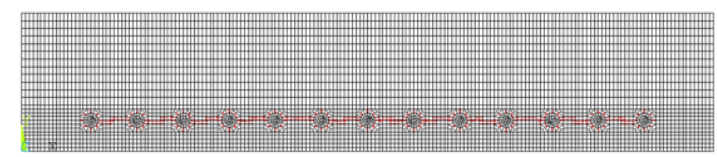

(a) $60 \mathrm{~mm}$ Spacing $(\mathrm{step}=88)$

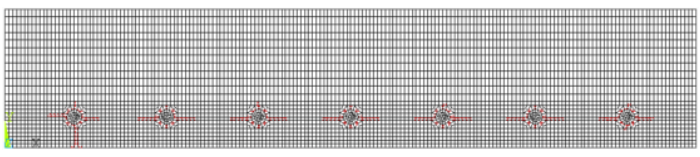

(b) $120 \mathrm{~mm}$ Spacing $(\mathrm{step}=111)$

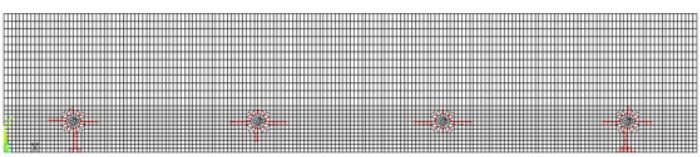

(c) $240 \mathrm{~mm}$ Spacing $(\mathrm{step}=114)$

Figure 18. Initial crack patterns

\section{Analytical Crack Propagation Results and Discussion}

Cracks developed at two stages for the specimens with $120 \mathrm{~mm}$ and $240 \mathrm{~mm}$ spacing (Figure 19). After vertical cracks initially appeared, cracks developed horizontally from each rebar with rust expansion (Figure 19a-1 and Figure 19b-1). The horizontal cracks eventually joined together between rebars (Figure 19a-2 and Figure 19b-2). Cracks to the left and right sides were different from the experimental crack propagation in that the cracks were parallel to the bottom of the specimen. As well, there were more vertical cracks. The progress of horizontal cracks between reinforcing bars was approximately similar to the experimental results. From the analytical crack propagations, it is apparent that cracks in the horizontal direction prominently progress after crack initiation due to rebar corrosion. 


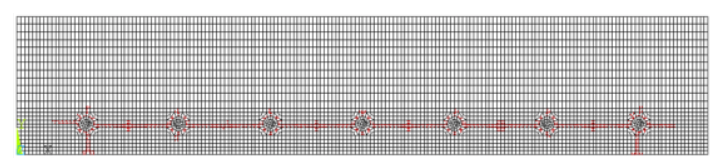

(a-1) 120mm Spacing (step=152)

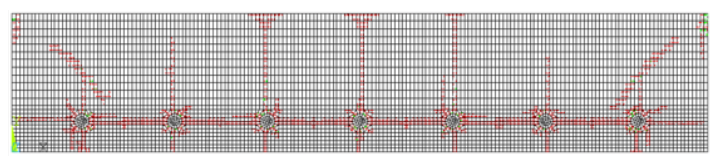

(a-2) $120 \mathrm{~mm}$ Spacing $($ step $=800)$

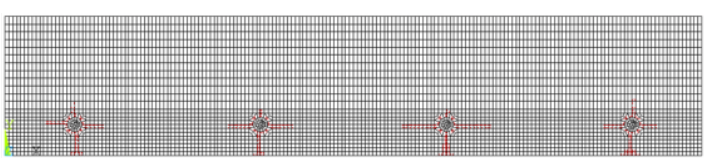

(b-1) 240mm Spacing $(\mathrm{step}=153)$

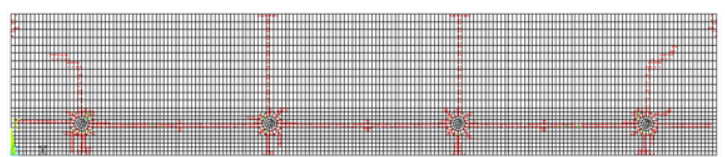

(b-2) 240mm Spacing (step=778)

Figure 19. Crack development

\section{CONCLUSION}

Crack initiation patterns and crack propagation due to corrosion were investigated for reinforced concrete slabs embedded with multiple reinforcing bars with $60 \mathrm{~mm}, 120$ $\mathrm{mm}$ and $240 \mathrm{~mm}$ spacing. Rebar corrosion was accelerated using an electric corrosion test. A numerical analysis was also carried out to verify the experimental results. From the experimental and analytical study, the following conclusions may be drawn:

1. Reinforcing bar spacing affects the crack initiation patterns. Small cover depth generates a vertical crack along the rebar. Narrow spaces between the rebar generates a horizontal crack.

2. A corrosion amount at occurrence of corrosion cracks was approximately 50 $\mathrm{mg} / \mathrm{cm} 2$ in this study.

3. In crack propagation, the horizontal direction between rebar was dominant rather than the crack initiation patterns for reinforced concrete slabs. The progress of the horizontal crack makes it difficult to observe on the concrete surface. In the case of concrete slabs, it was considered that methods other than crack observation are necessary for long-term maintenance.

4. In order to apply the outcome of this study to a real structure, it is necessary to conduct an exposure experiment in a natural environment. However, this study may be useful for the maintenance of reinforced concrete slabs with multiple reinforcing bars.

\section{REFERENCES}


1) Japan Concrete Institute (JCI). (2016). Concrete diagnosis technology, Basics.

2) National Association of Corrosion Engineers (NACE). (2012). Corrosion control plan for bridges, A NACE International White Paper.

3) Tran, K K., Nakamura, H., Kunieda, M. and Ueda, N. (2012): Analysis of crack propagation behavior in concrete due to multi-rebar corrosion, Journal of Structural Engineering Vol.58A, JSCE, pp.844-853. 